\title{
TRANSCRIPT OF THE 2008 LiVE SYMPOSIUM PANEL DISCUSSION*
}

\author{
Editor's Note
}

The following is a transcript of the live panel discussion presented on March 19, 2008, in the Wynn Courtroom of the Indiana University School of Law - Indianapolis, following the $2008 \mathrm{McD}$ onald-Merrill-Ketcham Memorial Lecture and symposium. The McDonald-Merrill-Ketcham Memorial Lecture and live panel discussion are presented annually by the Indiana Health Law

* The Indiana Health Law Review and the William S. and Christine S. Hall Center for Law and Health at the Indiana University school of Law - Indianapolis thank the following speakers for participating in the symposium and providing their unique and informative perspectives on healthcare reform in America, as well as for reviewing and allowing the Indiana Health Law Review to Publish this transcript.

James Buechler, M.D.

Director Emeritus,

Richard G. Lugar Center for Rural Health

Aaron Carroll, M.D.

Assistant Professor of Pediatrics in the Children's Health Service Research Program, at the Indiana University School of Medicine, and

an Affiliated Scientist at the Regenstrief Institute for Health Care

Matthew R. Gutwein

President and CEO,

Health and Hospital Corporation

David Orentlicher, M.D.

Samuel R. Rosen Professor of Law,

Co-director of the William S. and Christine S. Hall Center for Law and Health

Eric Schmitz

Regional Vice President,

Network Development Anthem Blue Cross and Blue Shield

Kevin Speer

Chief Strategy Officer,

Saint Vincent Health

The Indiana Health Law Review would also like to give special thanks to its Executive Business Editor, Mr. Jacob V. Bradley, its Executive Managing Editor, Mr. Mark E. Douglas, and Ms. Margie A. Welsh, Coordinator for the William S. and Christine S. Hall Center for Law and Health, who worked tirelessly to make the 2008 symposium a truly memorable event. 
Review and the William S. and Christine S. Hall Center for Law and Health. The live panel discussion is, by tradition and design, a moderated and unscripted exchange of arguments and counter arguments generated by the dynamic tension existing in current issues pertinent to practitioners in the fields of both law and healthcare. To preserve the dialectic flavor of the 2008 live panel discussion, the portion of the transcript presented here has been edited in form but not in content. During the editing process, a distinct effort was made to retain both the original tone of the panelists' remarks and the verbal mannerisms of the individual panelists.

\section{HEALTH REFORM IN AMERICA: GETTING BEYOND IDEOLOGY TO TRUE REFORM}

March 19, 2008

DR. ORENTLICHER: Thank you. It's good to be here, good to see such a nice turnout, and we've got a great panel. It seems to me that today there exists an opportunity, a window, to bring about true reform of America's healthcare system. We all remember 1994 when it seemed like we were actually going to get healthcare reform and universal access. A lot of time and effort was dedicated to developing possible solutions. Indeed, the Clinton Administration alone employed the services of 400 experts. However, in spite of all the effort, that window closed without getting true reform. But it looks like we've got another one of those windows of opportunity. The leading presidential candidates are all talking about it; and it's a major part of their platforms. So that's the question. Will it happen? What are the prospects? Whether we have Barack Obama, Hillary Clinton, or John McCain - and it seems like we're going to have one of those Administrations - are we, as a nation, going to achieve true healthcare reform? And if we do, what is it likely to look like? What should it look like? Those are the questions with which I would like to begin our discussion. Dr. Buechler, would you please start us off? What are the prospects, do you think, and will we get to the right place this time?

DR. BUECHLER: Well, it is interesting. When President Bill Clinton took office, there was a great hope that we would have healthcare reform, something I was quite interested in at the time. So I wrote Hillary Clinton a letter in the interim before President Clinton took office. I said, "I don't know what your role is going to be in this new Administration, but we really desperately need some changes in our healthcare delivery system." And she wrote back to 
me, actually. I've still got it. It's a little postcard. She said, and I'm paraphrasing here, "I don't know what my role is going to be either, but I'd agree that we need some changes in our healthcare delivery system."

In retrospect, we should have known that the Clinton plan was going to fail. In part because it happened at the beginning of an Administration that was not prepared to make the really hard decisions that you have to make about healthcare reform. The special interests ruined that opportunity, in my estimation, plus the plan wasn't a very good one. But now we have another window of opportunity, and things have gotten a lot worse in that time.

The access to care in our country is appalling especially in rural and innercity areas, areas where I've worked really hard to develop assistance projects and provide care. It is appalling. The World Health Organization even says that some parts of the United States are like a third-world country. So despite spending over $\$ 7000$ per person in the United States per year on healthcare, by far the highest expenditure, we rank the lowest among first-world countries. One good statistic that I like to use to help people understand how significant the problem really is, is the measure of healthy years lived. That's what we want. We want to be healthy for as long as we can be. We rank twenty-eighth there, between Portugal and Slovenia. That's our healthcare delivery system. So there is a great opportunity, I think, for healthcare reform now.

What should it look like? I'm going to give my opinion, and then I'd like to hear what others think. I think it should look like this (indicating a Medicare card). My Medicare card - my public part of the partnership, my Medicare supplement card issued by an insurance company - it's Plan F. I am sure that you are all aware that there are plans for Medicare supplements. They're all the same. Every Plan F is exactly the same. You can choose your plan, and you know that you are going to get exactly the same plan. And here is my Part D card (indicating a Medicare card) - this is my prescription card. Now, there are some problems with this system, but they'll get resolved eventually. In any case, when I go to the doctor I hand this card to the front office. When I do, they know exactly what my Medicare coverage is, they know exactly what Plan F coverage is, and if I need a prescription I know I've got my Part D coverage. They know what that is too. So there is no question about what my coverage is.

Medicare takes care of the oldest, sickest, and disabled portions of the population in the United States of America. Administrative costs - that means dollars that do not go towards healthcare in any way, shape, or form - for healthcare spending in the U.S. is about thirty-two percent as compared to sixteen percent in Canada. And does anybody want to guess what our inefficient public system administrative expense is? Does anybody know? There are probably some people here that know.

RESPONSE: About three percent?

DR. BUECHLER: Yes, about 3 percent. That's what it costs Medicare to deliver Medicare dollars. It's actually a pretty efficient system to administrate. 
So moving down the Medicare age and making it mandatory for all would be one easy solution to the healthcare crisis. We heard in an earlier presentation that people don't want, mandatory programs, but you have to have both the healthy people and the unhealthy people in a system. You cannot cherry-pick benefit recipients. We see this a lot in medicine today, insurance companies do it and specialty hospitals do it. There are all kinds of horrible approaches to medical care that rely on it, and I hope that we can talk about the problems associated with these approaches today. But I do think, and this is my personal feeling after thirty-eight years of seeing patients and seeing what they go through, that if I have a Medicare patient walk in the office and hand me this (indicating a Medicare card), they're going to be satisfied. So that's my assessment of healthcare reform.

\section{DR. ORENTLICHER: Dr. Carroll?}

DR. CARROLL: Let me be very clear upfront. I'm a health services researcher, so I always come down on the side of science and empirical research. I ask, "What does the evidence and research show us?" And when I talk about healthcare reform, I talk about health insurance. The slates are always full of new facts and figures that can help us learn about both our own healthcare system and the healthcare systems of other countries. And because such information is readily available, my views on the subject of "change" have changed over the course of my lifetime. When I began researching these issues, I approached healthcare research from an ideological or rhetorical standpoint, but over time the evidence really has, to some extent, pointed in another direction.

It's very hard to argue from any point of evidence that the United States' healthcare system is a good one. It does not matter what metric you pick for judging the quality of our healthcare system - be it infant mortality, be it maternal mortality, be it the percentage of people we immunize correctly, be it how many people are happy with the healthcare system, be it the number of preventable life years lost. It does not matter what metric you pick. We're pretty much at the bottom of the industrialized nations, which is frightening, considering that we spend two to three times more per person than any other healthcare system in the world. Indeed, at this point we are paying over two trillion dollars a year. And if you believe in the free market and you believe the rhetoric of what we've all been told, then by spending that much money we should be seeing dramatic results and significant returns. We don't. We have, based on any metric of quality, one of the worst healthcare systems in the world, and perhaps the worst healthcare system of all of the industrialized nations.

So you would hope we'd have phenomenal healthcare access. After all, if we're not getting quality, then at the very least everybody should be able to get access to the basic benefits of the system. But as we all know, forty-seven million Americans have no healthcare insurance. That's forty-seven million Americans, remember, out of the total population who are not over the age of sixty- 
five, because everybody over the age of sixty-five has Medicare. That's fortyseven million Americans, who are not extremely poor, because all of them have Medicaid. That's forty-seven million Americans who are not in the military, because military personnel have VA insurance. That's forty-seven million people out of the rest of us. It's a huge population. That's also forty-seven million people who lack health insurance for the entire year, not that portion of the population who lack health insurance for six or nine months. If you extend the accounting to that last group, the number of uninsured Americans likely jumps to over eighty million uninsured a year. That's a huge number of people without healthcare.

If you've heard the arguments against moving towards a national healthcare system or Medicare for all, then you know that as soon as we start talking about a nationalized system, everybody throws out concerns about rationing and waiting lines and things like that. However, if you don't think we're rationing healthcare in this country already, you're really putting the blinders on. We ration by whether or not you have insurance. Forty-seven million Americans have no access to the system. That's rationing. Also, these days if you're from the medical environment and you try to lock in a time to conduct a CAT scan or an MRI, or you try to get an appointment as a patient, there's always a waiting list all the time. The idea that somehow there's not wait times for things already in this country is to some extent ignoring the real picture - it's just how we choose to ration. Should we ration based on good evidence about whether to cover the things that are most cost effective in our society? Should we ration by which drugs work the best and provide the most value? Should we ration by which procedures we know have the best outcomes? Or should we just ration on money? So given that we ration healthcare already, it's clear that we're also doing poorly with regard to access.

So then, if we're not getting good quality, our costs are through the roof, and our access is terrible, we have to ask if we have the will to change the system. And this is where you get the common argument about how the United States will never accept any sort of major reform, and it's a very powerful argument. People in this country are scared very easily. However, the arguments made today against healthcare reform are virtually the exact same arguments that were made years ago when people opposed the passage of Medicare. "It'll be the death of the system." "It'll be socialized medicine." "It'll be the worst thing that'll ever happen." "There'll be rationing." "There'll be less quality." "It'll cost us everything in the world." "It'll be incredibly inefficient." All these statements were made about Medicare, and today you hear them in discussions about national health insurance.

Now, Medicare was very difficult to pass, but they got the political world together and they did it. And there's not a politician alive today that's going to run on a platform for repealing Medicare. Nobody thinks Medicare's a bad idea. Oh, it's underfunded, and it could work better in many different ways, but a lot of its problems are narrowly related to money. And how do you fix the problems? How do you eliminate waiting lines and rationing? Simple, you just 
to throw more money at the problem. The reason that a lot of other countries have rationing and have difficulties with lines is because they underfund their systems. We're already used to paying two to three times as much as everybody else. A very well-run national health insurance system in this country, with the kind of money that we're willing to throw behind it, would very likely be the best in the world.

As Dr. Buechler here said, Medicare is the most efficiently run approach to healthcare in this country. It's the most efficient form of health insurance, and it lacks the red tape that you normally see. Usually when I talk about this issue I look at and discuss the empirical evidence. According to current evidence we have terrible quality, unbelievable costs, and terrible access. We're failing in every realm. Moreover, the evidence shows us clearly that every other industrialized nation that has approached the healthcare problem differently has better quality and better access for lower costs. This suggests to me that what's really necessary to change the healthcare system in America, is a change in political will.

So the question we began with was, "Is there an opportunity here?" Absolutely, more and more people every day are fed up with the system. At this point, depending upon which survey you believe, somewhere between twothirds and three-quarters of Americans favor health insurance reform even if it means higher taxes. People don't favor the war if it means higher taxes. I mean, we're not willing to pay higher taxes for anything, but people are actually willing to say they'd pay higher taxes for health insurance. A significant majority of doctors are in favor of national health insurance. Really, the only groups that don't appear interested in national health insurance are special interest groups. Therefore, we have to just decide is this a time for change? It's a matter of political will. And hopefully, there'll be leaders. I don't care from which side of the aisle, because I' $m$ not ideologically involved in this. We have to have leaders who are actually willing to exert the political will to make some significant changes happen.

\section{DR. ORENTLICHER: Mr. Gutwein?}

MR. GUTWEIN: Thank you. Well, I'm shocked by the communist socialist rhetoric I just heard from this side of the table.

DR. CARROLL: There you go.

MR. GUTWEIN: What I believe Dr. Buechler and Dr. Carroll were describing is the desirability of - I think what's called in the industry, a singlepayor system - which is what we have with the Medicare system and which is what most other countries have as well. It might be best described as the socialist communist system. But it is the system that every major industrialized nation in the world has except for one, and that's us. And as has already been described, we are the system that has the highest cost, the lowest quality, the 
least access, unconscionable racial health disparities, and incredible bureaucracy. So why don't we have the single-payor system?

Getting back to Dr. Orentlicher's questions though, "Are we going to have health reform, and what would it look like?" I suppose it depends on how you define reform because there is, I think, a lot of reform going on right now. The system is very dynamic. It's changing all over the country. Here in Indiana I think some very positive reform measures were recently proposed by Governor Daniels and passed by last year's General Assembly that expanded access to healthcare to a number of populations that otherwise would not be eligible for Medicaid and could not afford private insurance. That opened up slots (access to medical care) to about 125,000 previously uninsured Hoosiers, and I certainly would call that reform. There are lots of other reforms going on around the country too, in Massachusetts, California, Florida, and Arkansas. I think there's a lot of reformative activity going on around this.

The question, I think, is are we going to get to the point that the two doctors proposed, which is the same point that every other major industrialized country has gotten to except for ours. There is no serious proposal on the table right now that actually suggests that we ought to have a single-payor system. Senator McCain is not proposing a single-payor system, Senator Clinton is not proposing a single-payor system, and Senator Obama is not proposing a singlepayor system. They're all proposing a sort of high route to what we have now; an expansion of the role of the federal government in subsidizing care combined with private healthcare insurance to augment that approach.

Is that a place where we ought to be? Doctors Carroll and Buechler have already stated that that's where we ought to land. And I'll confess my sins. I think that ultimately our country will get to a single-payor system, but the change will be incremental. I don't think we're going to get there with a single proposal by the next Administration, whichever Administration that is, and all of a sudden adopt a single-payor system. I think the kind of approach that's being taken right now, which is small steps toward expanded public funding of healthcare with an expanded risk pool that is less expensive to administer and less expensive to fund, is one way to get there.

So why do we resist that in this country? I've sort of been making fun by referring to the socialist communist system. Why are we so adverse to a singlepayor system? I think it is a curiosity. I think that there actually are very basic, fundamental and economically sound reasons why the single-payor system is the most economically prudent system to fund healthcare. In other words, it is consistent with economics. It's not anti-economic. And the reasons are very simple. Insurance is a risk pool. I want to make it clear that I am not in any way anti-private insurance. In fact, I'm certainly not anti-Anthem. I think Anthem/Wellpoint is a terrific company that operates with incredible efficiency, an efficiency which benefits all Anthem policyholders. And Anthem, all insurance companies by and large, operate within the rules that they were given, but I think that certain elements of the rules constrain them. And that constraint is this: Insurance is a risk pool, and larger risk pools are cheaper to operate than 
smaller risk pools. Larger risk pools have lower administrative expenses and a greater ability to manage outliers within the risk pool. That's why the Medicare system, which is the single largest risk pool we have in this country, has lower administrative costs than lots of very small insurance companies that have very small risk pools.

It's just a pure matter of economics. If we can create larger risk pools insurers can reduce their costs. Which is exactly why Anthem's costs are so low: Anthem's now the largest insurance company in America, and they are able to take advantage of their large risk pool. Their strategy is exactly the right one. And so, if we can do that on a national basis, we will lower the administrative costs for everyone. In other words, the single payer system is highly consistent with economic principles. It doesn't represent an effort to get around the market. With that I'll turn it over to the true risk pool expert.

DR. ORENTLICHER: Okay. Mr. Schmitz? We do want you to have a job.

MR. SCHMITZ: Do I think there's going to be some of the right reform? Some of the concerns that I'm seeing are in the payment mechanisms that are out there right now, Medicare and private healthcare insurance. Right now insurers pay providers every time that there's a medical problem. We don't pay physicians and hospitals to keep you healthy. We pay physicians and hospitals when you're sick.

So one of the things that we're hoping to do with some of the reimbursement that we're looking at - and one of the jewels, I think, of Indiana's programs has been the Indiana Health Information Exchange ("IHIE") - the IHIE is building some information databases that can be shared among all payers Medicare, Medicaid, Anthem, and the like - so that we can actually start reimbursing physicians and hospitals based on their outcomes instead of just paying for every time you're sick. Not that physicians or hospitals do a bad job, but they earn their income when you're sick. So if there's a way that we can keep the providers in business to keep you healthy, I think that could create a better outcome for all of us.

It seems to me, that the current debate is focused on who should pay, and how many payers there should be. The current focus is not on the value equation of best quality for the lowest cost. And that's a problem, because low cost is necessary so that we, as an economy, can compete. Indiana has some of the highest-cost healthcare that I deal with. Wellpoint operates under the Blue Cross and Blue Shield license in fourteen different states. Indiana pays some of the highest costs per member.

So I'd like to throw this out in the debate on expanding access to care, and I think there was a good question here regarding access to care. Specifically, "What does access to care truly mean?" Does it mean that every individual should have a health insurance card or has the right, if you will, for a thirdparty-payor to pay for something? One of the things that I run into a lot with 
providers is the question of what Anthem pays compared to what Medicare and Medicaid pay. Medicaid pays - and Mr. Gutwein, you can correct me if I'm wrong here - pays less than twenty cents on the charged dollar.

MR. GUTWEIN: Medicade pays twenty percent of costs.

MR. SCHMITZ: Medicare, on the other hand, is paying about forty cents on the charged dollar. And other health insurers are paying sixty to seventy percent of the charged dollar. What I mean by the charged dollar is what the hospital charges, that's what is paid. So rather than talking about access to care generally, I should point out that we're already starting to see an access issue in Indiana around primary-care, an access issue caused by the decrease in the number of physicians going into primary-care. And right now we have a system in which private payers pay much more than what Medicare and Medicaid reimburses physicians and hospitals. As the single-payor system rolls out, seeing where our tax dollars are, I don't think that Medicare - let's say Medicare is the single-payor system - that Medicare's going to automatically increase the rates paid to providers to the level we, as private-payors, are now paying. I would assume that if there was a single-payor system, what commercial payers are paying now would be reduced, and providers would be getting paid what Medicare is paying. That could be a problem, because salary rates for PCPs are, I think, only a little over $\$ 125,000$ now. If you're seeing family physicians not go into primary care because of the economics today, what's going to happen if we go to a single-payor system that actually reduces the salary even further?

DR. ORENTLICHER: Mr. Speer? St. Vincent Hospital, what do you see there?

MR. SPEER: I would be remiss sitting in this law school if I didn't say before I begin that, as the representative of a not-for-profit organization, nothing I say should be considered an endorsement or commendation of any of the political parties or their agendas. These are simply my opinions or observations.

You asked a couple questions. I think I jotted them down correctly. One was, "Will we get to the right place." Because we started with Dr. Buechler, perhaps we framed the "right place" as being a single-payor system. If that's the "right place," then my answer is that I think it's unlikely we'll get there. Having spent a number of years lobbying for both the Indiana State Medical Association and the Hospital Association, both here and in Washington, D.C., I would suggest that government isn't going to change under any of the Administrations that we're looking at.

The other part of the question was, "What would a changed system look like?" Well, I think healthcare is already changing to accommodate what Dr. Buechler and Dr. Carroll are describing, $100 \%$ access at more efficient access 
points. From a savings in health perspective, our mission statement is that we have healthcare that works and that no one is left behind. We advocate for $100 \%$ access and $100 \%$ coverage, but we deal in a world in which those aren't always possible. Whereas we push and strive for those ends, we aren't there yet, but we are evolving.

When I say "we," it's more than St. Vincent. It's healthcare in Indiana. If you look at our demographics and the patient base in our state, we've seen an increase in premiums. It's not a reflection on Anthem, but the reality is that there has been an increase in premiums generally. We've seen the number of employees insured by their employer reduced. And we've seen an increasing number of people who have higher pay or higher deductible premium insurance plans. So if they are not using a health savings account, they may have the first $\$ 3000$ or $\$ 4000$ or $\$ 5000$ coming out of pocket. Those factors in and of themselves are forcing healthcare and the healthcare delivery system in Indiana to change, and probably change ahead of whatever Washington or the State of Indiana would like to see done. Because the healthcare providers are trying to adapt, trying to prepare for those things.

I think a couple of things will change in the next four years, no matter who's elected President or what the make-up of Congress is. I think we're going to see an increase in transparency. You're going to be able to, within the next four years if you can't already, go online and understand what the true cost of your care is going to be. If the first $\$ 3000$ or $\$ 5000$ is coming out of your pocket today, while two years ago your employer paid for it, now all of a sudden you care about the costs. So if you can go to Minute Clinic and get a diagnosis for your son's pink eye in five minutes and pay thirty-five dollars - it says on the sign on the wall that it's thirty-five dollars - rather than call your pediatrician and spend most of a day and a half trying to get your kid in for a checkup, and then pay sixty-five to eighty dollars out-of-pocket, that's going to drive change. We're seeing both physicians and hospitals react to that changing reality.

The healthcare system is going to change and it is changing. If you haven't experienced it already, it's changing right now in the state, becoming friendlier to consumers. It has to, not only for those people who have the higher out-of-pocket deductibles, but also for those people who don't have insurance at all. And I'll speak specifically about St. Vincent. If you're poor and can't pay in the state of Indiana and you come into a St. Vincent facility, we're going to give you a card that looks just like the insurance card you get from Anthem, and you can access our physician network, you can access our hospitals with that card, and receive care in a dignified manner. Today, you have to be consumer friendly to the poor. You have to be consumer friendly to those who are paying out-of-pocket. You have to be consumer friendly to the payers. Indeed, the payers are increasingly more interested in quality, and less willing to pay for mistakes, or to overpay for access generally.

Healthcare is changing around us in response to that. Governor Daniels passed very good legislation two years ago requiring hospitals to report on nev- 
er-events. That's drawing people's attention to it. You can go online and find out which hospitals have more never-events than others. Patients care about that. So I would argue that whether or not one of the elected officials changes healthcare, I think healthcare is currently changing without their help and that it's changing around those issues. It's going to become more consumer friendly, more transparent, and you're going to understand what you're buying and what you're paying for. The IHIE is a great example. The evolution of that type of program for the providers in Indiana and nationwide would be the key to changing how healthcare is delivered. If those things happen in the next four years, I think we're going to see significant change in our healthcare delivery system. But will we become a single-payor country in the next four years? I don't believe so.

DR. ORENTLICHER: None of the leading Presidential candidates have come even close to advocating that. Obama's hope is that by making it more affordable, people will voluntarily take up insurance, clearly less than a mandate.

You're talking about the move toward patient empowerment achieved by telling patients what procedures and services are going to cost. Recently, we've heard a lot about patient responsibility in terms of costs, and we've heard even more about patient responsibility in terms of smoking and other risks for healthcare. I think that there are two ways to look at this. One approach is to view these changes as good, shared responsibility. Although as Professor Annas said, what does it mean to say shared? Either you're responsible or you're not. The thrust behind shared responsibility though, is that patients all make some individual contribution, a contribution that is individual in the sense that if we just stopped smoking, exercised, and ate better we would solve all the problems facing healthcare. If we all knew what we were paying for, we'd be more responsible. We wouldn't run to the doctor every time we saw a Lipitor commercial and ask for a new prescription. As Calabresi and Bobbitt would say in Tragic Choices, this is a way to hide the fact that we are rationing care and not giving everybody the care they need. So instead of taking the responsibility ourselves and saying up-front that we're not going to give some people care while at the same time giving other people care, we are trying to put the blame on the patient in kind of unfair way. Are we suggesting that the patient really has more responsibility than they deserve? Is this a way for society to avoid its obligation to make sure that people have the care they need? What about this move toward patient responsibility?

MR. SPEER: Well, I don't think that it's an attempt to shift blame onto the patient. Indiana is one of the heaviest states. We're one of the states with the highest incident of smokers. We're arguably the least healthy state as a result of those statistics. All you have to do is talk to Dr. Buechler about the patients he sees. I'm not going to speak for you, Doctor (Carroll). Dr. Buechler has been managing obese individuals, smokers, and diabetics. That can be a 
difficult task, depending on the individual's mindset regarding their disease and their desire to improve their health.

There have been a number of initiatives by employers in central Indiana to incentivize individuals to lead a healthier lifestyle. These initiatives include, providing healthier food in cafeterias, and reducing the portion of the out of pocket insurance premium paid by employees if they engage in certain healthy lifestyles. I don't necessarily think or haven't noticed any great change in people's behaviors as a result of these initiatives. But trying to incentivize people to do those things, and trying to educate them about the harm those things cause is justified. Even if such incentives don't help the incentivized person, maybe they help their child or their child's child. I think we have to talk about it. We have to be aware of it.

We try very hard as a healthcare system, and we have seventeen hospitals in a forty-five county service area. One of the things we're very proactive about is smoking cessation and we try the best we can to carry that message throughout our service area. We've had marginal success, I think, at St. Vincent in getting people to stop smoking. So I don't think it's an attempt to shift blame or shift the cost. But, to give you one person's opinion, I think that if we can encourage people to be healthier, we ought to do it.

MR. SCHMITZ: I would have to agree with Mr. Speer's comment that we have very little evidence to support any assertion that there's been a lot of change out there. With the increase in deductibles, however, employers do have the potential of reducing their costs. But, I think what employers would do - and you see this with many employers that have profit-sharing plans, the purpose of which is to actually get the employee invested in the performance of their organization - is impose a higher deductible on health plans. So in a sense, the cart truly is a little bit in front of the horse on this one.

Anthem has a comparison tool that is available to all of our insured clients today. Let me give you a brief overview of the tool. It lists thirty-nine different procedures. Right now if a member or any patient goes to Wishard or St. Vincent they really don't know how much it's going to cost. Providers are not intentionally vague with regard to cost. It's just the historical nature of our system. First you receive the services, and later, when you get the bills, you see the cost associated with each line-item. If you think about a bill for a car, the bill would list the cost of the tires, the shocks, and so on. The big difference is that the costs associated with cars are very transparent and easy to compare. But, when a consumer like me tries to determine the cost of having his or her gallbladder removed at St. Vincent, as compared to the cost at Wishard or at one of the surgery centers, there is no easy way of comparing the costs. So we built this tool to aid in the comparison. Tools like this are needed if employers are going to get their employees to act as consumers in the healthcare system. If folks like Anthem or the service providers don't have these tools available to inform patients about cost, the patient will really never know what to do. They'll keep going to the same place. So we need more robust tools that actu- 
ally show quality outcomes and overall costs. That would allow us to clarify the overall value proposition. Such tools are and would be very useful, but I don't think that the transparency they provide can cause a true shift in overall patient responsibility.

MR. GUTWEIN: Our lifestyles that we lead. I'm hoping the doctors over there can explain to me why the French can smoke, drink burgundy every night, eat foie gras, never run, and still stay skinny. It's wrong, and we need to figure out why.

Healthcare reform is multifaceted, and I'm an enormous believer that we ought to do everything we can to reform our lifestyles. We shouldn't smoke. We shouldn't drink wine every night - every other night maybe - but not every night. We shouldn't be eating McDonald's hamburgers three times a day. We ought to stress those good behaviors because they are critically important. I also am a believer in economic incentives for people to alter their conduct.

I do believe that economic incentives work. In fact, I see Dr. Virginia Cain, the Director of the Marion County Health Department, has joined us today - Nice to see you, Dr. Cain. We use economic incentives all the time in programs that Dr. Cain and I are working on at Health and Hospital. For example, at-risk pregnant mothers who are at risk of having low birth weight babies, we provide those women economic incentives to go and get their wellbaby care visits, to take their vitamins, and to do all those very important things. When they do, they get little coupons, and they can take those coupons and get car seats. We actually partnered with St. Vincent in one of our clinics on this thing. And it turns out that those economic incentives work and that the young mothers to whom we can offer a car seat or a free crib or baby clothes come in and actually get their visits. As a result, they have full-term babies and fewer premature deaths. So incentives work and I think we ought to use them all over the healthcare system.

Having said that, I am highly dubious that what I think is called consumer-driven healthcare can offer the kind of huge gains or the radical reforms that will bring down healthcare costs to the levels that exist in other countries. In other words, that consumer-driven healthcare can save us seventy-five percent of our total healthcare costs, which is how much more we spend than the Canadians. The Canadians spend only about twenty-five percent of what we spend on healthcare. The French spend about fifty percent. In other words, there are not fifty percent gains to be had in consumer-driven healthcare, and here's the reason why: It' because - and these are basic economic reasons - it turns out that economic incentives only work for items that have what economists would call an elastic demand. In other words, where the price actually can affect conduct incentives are effective. However, really expensive healthcare procedures are inelastic. In other words, we do not shop for price when we need something that is really expensive in healthcare.

I'm an enormous believer in the market. When you need a pair of blue jeans, the market is perfect at saying, "If you want to go down to Goodwill, you 
can spend fifty cents for a pair of blue jeans. If you go to Old Navy you'll pay ten dollars. If you go to Levi's, you'll pay thirty dollars. Or, you can even find a place to pay $\$ 200$ for blue jeans if you want." In the market, you have those choices. But when you have a heart attack and you need a heart catheterization immediately, you do not want your doctor to come to you and say, "Would you like a Goodwill heart cath? It's one dollar. Slightly used, but it's pretty good. Or, you could go with the Old Navy heart cath. The kids love it. It's a great bargain for people on a budget. Or you might choose the basic Levi heart cath, its price and quality is sort of in the middle. We could even give you the Dolce \& Gabbana heart cath." That's just not the way you buy healthcare when it's really expensive.

What economists would say is that healthcare is completely inelastic. What you want is the doctor that can fix you perfectly and immediately, irrespective of the cost. That's what we expect of our healthcare system. Mr. Schmitz is exactly right. Different systems do have different costs. That's the case. But, what we expect of our system is that every doctor that touches us will provide the highest quality care available while performing to nationally accepted standards. That's what we want to pay for. Or, what we want someone else to pay for. We don't want an Albanian medical student who's never done a procedure before working on us. We want a real doctor. That principle, that major healthcare costs are inelastic, is a fundamental aspect of our system, and that's why there are important but limited gains to be had from incentive or consumer-driven healthcare.

There's one other basic economic principle that's at work here too. That is, healthcare has what economists call economic externalities. In other words, the purchaser of a healthcare service does not bear the full economic cost of his or her decision. To expand upon an example given by Dr. Annas earlier, if a person lands at the Indianapolis Airport today and is a carrier of SARS, we could treat that SARS patient perfectly with $\$ 500$ of antibiotics. So we could grab her and say, "You've got SARS." And we could pay her $\$ 500$ so that she can seek treatment. But, she might say, "I'm feeling pretty good today. Therefore, I'm going to take that $\$ 500$ and I'm going to buy food for my children, pay the rent for our apartment, and put the deposit down for school books so that my kids can get an education." That's how she might choose to use that $\$ 500$. If those are the choices she makes, and for her they make economic sense, then for her those decisions are the correct economic decisions. But, if she then gives SARS to her children, who go to school and give SARS to everybody else, suddenly we have a multimillion dollar epidemic, simply because she did not bear the full economic cost of the decision she made about healthcare. That is a principle that plays out every day in healthcare, and that's why an ordinary free-market healthcare system will not inevitably lead to the most rational and cost-effective result. Economic externalities are powerful in healthcare. So you can't expect ordinary free-market principles to have the same influence upon healthcare choices as they would upon a person seeking to purchase a pair of blue jeans, which have no economic externalities. 
DR. CARROLL: There are two main questions here which I really want to address. The first question is about "us." It's very tempting to want to believe that there's something special about Americans and our lifestyles - smoking, drinking, whatever - that drives up healthcare costs. The problem is that it's just not true. Our smoking rates are the lowest of the top ten industrialized nations, and our drinking rates are pretty much the lowest as well. It's just not true that these behaviors are driving up our healthcare costs.

There are some very obvious differences though. One is the way that we administer healthcare and health insurance across the United States. Obesity, sure, we could all be thinner and we could all eat better, and obesity is a problem in this country. But, in the scheme of things, obesity is a relatively recent issue, and our healthcare problems have been going on for a long, long time. The other difference is related to the idea of consumer-directed healthcare, and that one's complicated. Again, it's very easy to want to believe what I call, "the moral hazard," because it makes a lot of intuitive sense. The moral hazard is the idea that if we all had some skin in the game, we'd care more. In other words if I knew that my healthcare costs were coming out of my pocket, as opposed to someone else's pocket, I would be more careful with how I spend my healthcare dollar. There are a number of problems with this argument, this "moral hazard," the first being that somehow we don't all have skin in the game already. The idea that the taxes we're paying to Medicare, the taxes we're paying to Medicaid, and the amount of money that each of us individually pays for health insurance somehow doesn't count and that we, therefore, feel the need to spend willy-nilly.

The second problem is the idea that somehow healthcare is like any other product in this country. That if it was free, everybody would want it. I doubt that if colonoscopies were free many people in this room would start buying them by the dozen, or would say I need some extra chemo treatments this year, or maybe an open-heart surgery because now it's free. Most people don't want to get healthcare. It's not as if all of a sudden when it became free everybody would just immediately want more. Would some? Sure. People are always going to abuse the system. But the idea that giving consumer-driven healthcare to consumers is somehow going to control its costs has two real strikes against it, and if there are any take-home messages that I hope you get from what I'm saying I think they would be these.

The first is that this topic has already been studied. There was a study done by the Ram Corporation a number of years ago. It's really the only major randomized controlled trial of consumer-driven healthcare that I am personally aware of. The study found that when people who weren't used to controlling their healthcare dollar gained access to consumer-directed healthcare; they actually did spend less on unnecessary healthcare. It worked. The problem is that they also spent significantly less on necessary healthcare. Apparently, the average person can't tell what's necessary and what's unnecessary when it comes to healthcare. What they do is try to save money. This savings is not directed to 
some medical good. They just try to save money overall, which really doesn't work in the long run when healthcare related issues are involved.

The second - and this is probably the most important point - is that about eighty-five percent of healthcare costs in this country are spent by about twenty percent of the total population. Let me say that again. About twenty percent of people in this country are responsible for about eighty-five percent of our nation's two trillion dollars in annual healthcare costs. The chronically ill, people with care givers, people in ICUs, they account for the vast majority of our healthcare costs. None of that can be affected by an MSA (Medical Savings Account) program. After all, the expensive twenty percent blow through their deductible in the first few weeks of the year. What MSAs do is they allow people at the other end of the spectrum not to spend money. The top twenty or thirty percent of healthy people in this country spend nothing on healthcare each year anyway. So yes, they'll get all their money back, but we need that money to make the system work.

Insurance works by taking money from healthy people and using it to take care of the sick. Your car, when you have a crash, gets fixed by the money from people who did not crash their car that year. When your house burns down, the money to build it again comes from the people whose houses did not burn down. That's insurance. Insurance has to take money from the people who don't get sick and give it to the people who do. And if we return all the money to the people at the top end, the twenty, thirty, and forty percent of people that have no healthcare costs, nothing will change at the other end of the spectrum with the eighty-five percent of costs from the most costly twenty percent of the population. We wouldn't really achieve any significant drops in cost, and the system would likely fall apart.

The eighty-five percent or more of costs at one end of the spectrum are to some extent inelastic. We cannot make chronically-ill people use less healthcare. Unless we make a major change in our approach to dealing with end-oflife care generally, we won't be able to reduce costs by returning a few thousand dollars to consumers. So while these ideas rhetorically make a lot of sense, when you look at the economic realities involved and the true hard-core facts, they really can't be expected to make much of a difference in the longrun.

DR. BUECHLER: That was brilliant. And it's interesting, I've never met Dr. Carroll before - the young physician and the old physician - we agree completely. And the thing about it is that most physicians who are in the trenches doing primary-care and taking care of underserved populations will agree completely with what he has said. And I hope with what I'm going to say right now.

To begin, I want to ask a question. And I would like a show of hands, if you are comfortable doing so. How many people here don't have health insurance? One, and there might be another person or two who's also in a time of transition. Most of the forty-seven million people who do not have health in- 
surance are the working poor. Sometimes the wealthy are affected too, the upper fifty to sixty percent, but not very often. There are a couple reasons for that. First of all, I would venture to say every person in this room has an IQ above the national average of 101 or 102 , whatever it is. Now, half the people in the country have IQs below that. And if you don't think intelligence has something to do with healthcare and making decisions about whether you're insured or uninsured then you are out of touch, and you need to spend some time taking care of some of this state's underserved population.

Tell me, is that something you deserve, to have your IQ higher? Did you do something worthwhile in your life to make your IQ higher than the average? No. You may have grown up in a good environment, may have had some good parents, may have had a pretty good education, but inherently your ability to learn, transmit knowledge, and understand is a gift from our Creator. Be grateful for it. What does that mean to me when it comes to healthcare? Those of us who have been given much have to respond to those who have gotten less. It is easy to talk about taking responsibility for healthcare. But let me tell you, I've taken care of the underserved for thirty-some years. Many of them struggle every day, and they can't even take the responsibility to find and keep a job or get and keep their car running. When you work with the underserved, you go into houses that have no reading material - I hope you've heard of a program called Reach Out to Read, where we're trying to affect that - where kids are brought up with not a single thing to read in a house, and you ask them to take responsibility for their own healthcare or manage their healthcare dollar. You quickly realize that such an assumption of responsibility is just impossible for them.

Now, what does work? Primary-care works. And not just primary-care the way we have traditionally known it, but a new type of primary-care. It's one that you see in community health centers, FQHCs (Federally Qualified Health Care Centers), and rural health clinics. It's a kind of primary-care that we've tried to pioneer in some rural areas of Indiana: Multidisciplinary Healthcare. Multidisciplinary Healthcare is delivered to a population on a primarycare basis with the help of physicians, mid-level providers such as physician's assistants, nurse practitioners, social workers, and mental health specialists. It's a team of people providing healthcare to the underserved population.

What does that mean? It's a truism that a physician cannot be all things to all people - cannot happen. It will wear you out. It will exhaust you. But if you have a team of people providing healthcare to a population, it works extremely well and is very efficient. So when members of the underserved portion of the population have healthcare issues, and they have many, a multidisciplinary team is better able to respond than an individual primary-care specialist. The team serves as the primary-care provider and their costs are much lower in the long-run than those incurred by the individual PCP and a team of specialists. Can I prove it? The only good proof that I've seen is the study that was done by CMS (Centers for Medicare and Medicaid Services). They did a study, I think it was, in Iowa and they looked at populations of Med- 
icare patients, and they found that if you take a population of 10,000 Medicare patients, and you add a specialist to the physician population in that group of 10,000 , any specialist, the cost for every Medicare recipient in that group goes up about $\$ 700$ a year. If you do the converse, take that same group of Medicare patients, and add a primary-care provider, the costs to that group of 10,000 Medicare patients goes down by about $\$ 500$ or $\$ 600$ per person.

We have not come to grips with the primary-care crisis in our country, and no healthcare reform is going to work - none will work - unless we deal with the primary-care crisis. In recent years, the numbers of PCPs have dropped by at least half. There are some good reasons for this, and some are actually being addressed by Indiana University. It could be done better, but they're working at it. I don't know if Dr. Steve Leapman's here, but he's the one, "shining knight," at IU. He's really working on changing who gets into medical school, because that's a big part of the problem. See, your kids, a lot of them, are likely going to want to go to medical school. How many of them are going to want to go to Owen County, Indiana, and practice primary-care? Not very many I think.

The other thing is this, if we're going to have healthcare reform, it's going to have to be reform from the grass roots up. It can't come from the people in Washington. So it's going to take you people, a grass roots movement, to say, "We've got to change it." We've got to change it, and we have to do it in the best possible way. I'm sorry that I get a negative sense about healthcare reform from the insurance and hospital representatives on this panel. They make it sound as if we're going to end up with some disaster if what they're talking about happens. We need a unified, simple system. Didn't Dr. Annas say that? And there is nothing simpler than this (indicating a Medicare card), let me tell you, nothing simpler than this.

DR. ORENTLICHER: I have, I think, time for one more question before we turn to questions from the audience. I want to pick up on a couple points that have been made. That is, while we're waiting for overall national reform to change our system, other changes are being made, and there are some for better and for worse. It has been suggested that we need to place more emphasis on primary-care. So of the changes that the private sector can make or that government can pass short of an overhaul of the system - because, after all, the government could pay for performance - which of the options out there really are promising? If consumer choice, because of the problem with the chronically ill, has limited effectiveness, what really will work in terms of short-term, less than full reform, changes?

DR. BUECHLER: I'm not going to say where my politics are, but you might get a sense of them somewhere along the line. One thing that President Bush did well was this: He said, at the beginning of his first term, that we were going to have a community health center in every poverty county in the United States. That bill was finally passed. He got that through just a couple years 
ago. They provide access to care for people who have no access to care, and it's a good access to care. There aren't nearly enough of them. I don't know how many there are in Indiana, but they provide great access to care, and opening more of those clinics is something that could happen pretty quickly without a whole lot of federal money.

DR. CARROLL: I want to just reject the question outright, but I will try to answer it. I think that we don't want to let the "good" become the enemy. There have been a lot of proposals in the last few years that certainly would do some good. S-CHIP (State Children's Health Insurance Program) for example, which unfortunately got vetoed some time ago, was a great idea. The S-CHIP program has covered significantly more children with healthcare. No matter how much you think that people should be responsible for their own health, it's very difficult to say that kids are responsible for their own problems. Certainly, they didn't put themselves in the financial situation in which they find themselves. So covering all children, which seems politically reasonable, is something feasible that could probably occur. I want to reject the question outright, though, because I think that a comprehensive solution addressing all of the problems at the same time is necessary.

I think what you're seeing in Massachusetts, for instance, is what happens when you go piecemeal. The problem is, for example, that individual solutions to the rising cost of health insurance often seem to make sense at high levels of government. The problem is that health insurance is just too expensive. The average family plan for health insurance in this country costs about $\$ 12,000$ a year. That's the average. Not the high end, the average. Tell me how a family who makes $\$ 40,000$ a year with three kids after taxes is supposed to have an extra $\$ 12,000$ laying around. Subsidization works, but I don't care how much you subsidize, it won't solve all of the problems for a family in this situation. Give them all their federal taxes back, $100 \%$ of them. What do you think they're paying, $\$ 3000$ ? They still can't pay the $\$ 12,000$ a year for a family policy. So you have to keep raising the level of subsidization.

There's a lot of pushback on subsidization efforts because it's intuitively difficult for people to grasp how a family making $\$ 75,000$ a year can't afford health insurance. A lot of people just can't get their minds around that. It's just true. And so, while I think that there are some incremental reforms out there, I also think that they are all doomed to failure in the long-run. They're not going to contain costs. They're not going to take advantage of the large risk pools that insurers rely on. They're not going to necessarily cover everyone, even with chronic diseases. They're not going to always cover preexisting conditions. They're very difficult to enforce. Ultimately, they're very anti-public health.

So again, I would not want to be the enemy of the "good." If you have the political will to pass legislation, I'm voting for it. I'm not getting in your way. But I think that if you truly want to talk about reform that's going to solve real problems, you have to think about Medicare's history and you have to be will- 
ing to accept the fact that we had these problems before, and everybody made the exact same arguments. We still somehow got Medicare passed. Also, every other industrialized nation's dealt with this. I don't think they're necessarily that much smarter than we are, but they found solutions. And so, the arguments suggesting that we can't get this accomplished really don't stand up.

MR. GUTWEIN: I would propose a five dollar cigarette tax. That would be a short-term solution. I'm incredibly grateful to our General Assembly for increasing the cigarette tax, and I would raise that tax through the roof. What's more I would do exactly what Dr. Buechler suggested and take money from that tax and invest it in primary-care, which is absolutely the biggest bang for the buck out there. That would have an immediate and profound impact on the state of our health nationally.

MR. SCHMITZ: There are a couple of things that I'd like to address. I think Dr. Buechler brought this up quite well. The first is true support of primary-care. I think that support for primary-care is one of the ways that we can really help affect an overall change. I also think that what Mr. Gutwein brought up regarding the cigarette tax is a good idea. After all, a lot of that revenue went to fund Healthy Indiana. I also think that Mr. Gutwein mentioned earlier that Indiana is at the forefront of some good healthcare reform, and of getting healthcare coverage out to individuals who don't have it right now. One of the components of that initiative was bringing skin in to the game. Giving the population of individuals who has never had healthcare insurance skin in the game by providing them with a tool, like a MSA. I also think that one of the incremental steps that we could take on the road to reform would be to increase transparency.

We have a lot of great things in Indiana and in the U.S. generally. But, the healthcare system is very complex. I've been in the game now for twenty years, and boy, I'm not ashamed to admit that I still get confused every day. It's a very complex system. I think that there is hope though, and that solutions are possible. One of the things that we looked at with Wellpoint, and we have thirty-five million members, is the incremental value of apparently small savings. If for example, you're able to save a penny per month, if you will, on thirty-five million members, that's a whole lot of money. If you think about the smart use of the healthcare system and what Dr. Carroll has brought up, you have to admit that you can't save a ton of money on those people who have chronic illnesses. There is some potential to save by getting those folks to the right care setting, but if you are able to save a penny here or a penny there, that can be used. It adds up, and it doesn't have to go into the healthcare system.

If you look at some of the hospitals that we have in our comparison, which focuses on Central Indiana, we see extremes. The average price of a newborn delivery, the total price - including the physician and the delivery itself - runs about $\$ 7300$ for per delivery. There are parts of our state right now where it costs over $\$ 13,000$ for the same delivery. Why does a delivery cost twice as 
much an hour away from Indianapolis as it does in Indianapolis? That's just wrong. That's where increasing transparency by helping folks and their employers look at their healthcare dollars could be very beneficial. With transparency, local employers could work with hospital administrators and physicians to look at how healthcare dollars could be used more efficiently in their communities. Not to beat up on the hospital or the physician. That's not what I'm after. I'm just suggesting that any viable solution must help us get our arms around the needs of the wider community. Mr. Gutwein mentioned the use of the incentives. Are mothers not going in and getting their prenatal testing? Is that an epidemic situation, if you will, in a given county? That could be what's driving the cost of healthcare, but until we get our arms completely around these questions and deliver full transparency, we're not going to know what the real cost drivers are.

MR. SPEER: For those of you who aren't aware, a substantial part of the state of Indiana is designated by the federal government as medically underserved. Marion County is a medically-underserved area. Not at seventy-sixth and Spring Mill Road, but at tenth and Central. So the quickest and easiest win, in my opinion, and the win that can be done tomorrow is to increase incentives for primary-care. We have a declining number of applications for students entering medical school. Of the students who are entering, a declining number of those are pursuing or interested in a primary-care specialty. Why? If you talk to those students when they're undergrads making the decision to go to medical school, once they're in medical school, once they're in a residency program, and once they're in practice for two to five years, or at any point in time, it's hard to find one that doesn't bring up the reimbursement and economic issues of being a primary-care doctor.

Mr. Schmitz pointed out - and I think he's dead on - the average reimbursement for a family practice doctor in the state of Indiana is around $\$ 125,000$ a year. Dr. Buechler brought up the issue of IQ and the fact that the IQs of people in this room are above that of the average. The position of any individual entering medical school's IQ, I would argue, is perhaps above most of those in this room. And they have choices as to what they can do or where they can go with their careers. There are exciting innovative opportunities out there which will reimburse them better than a PCPs salary of $\$ 125,000$ a year. What's more, most of the other enticing opportunities open to these students won't require them to incur $\$ 200,000$ worth of student loans.

That system, in my opinion, can be easily fixed. It can be fixed through, increased reimbursement by federal and state government, Medicare and Medicaid programs, and incentives around tuition for students who are willing to enter primary-care, and willing to follow through with that decision and then go locate in one of the medically underserved areas in the state of Indiana. I also think that you could tweak Indiana State's program. Indiana State has a direct admit to medical school program for high school students, and many of those students start off wanting to go into primary-care. But, that program can't by 
itself resolve the shortage of PCPs, because students are free to choose another specialty at will once accepted to the medical school. We need to create some incentives to keep students interested in becoming PCPs. We have to fix the system because right now the incentives just aren't there to encourage someone to go into that specialty.

I was also kind of hoping we'd get into a discussion today about some of the growth and building of healthcare facilities and other things that is going on, not only in Central Indiana but around the state. One of the questions I ask every day as I drive by them, and I participate in the planning for some of them, is who's going to work in those facilities? We aren't going to have the nurses or the doctors to staff them. So again, we need to create incentives. Lastly, I'd say that maybe we need to look at building an additional or second medical school in the state of Indiana, a medical school that's maybe focused just on primary-care. My solution's to fix primary-care. Those are just some easy ways to do it.

DR. ORENTLICHER: All right. Let's turn to some questions from the audience. As we're struggling to achieve national healthcare reform we've seen states like Massachusetts and Maine step up. Should the federal government do more to support state healthcare reform initiatives? Can it be done on a state-by-state basis or are there too many problems? Specifically, with Massachusetts' plan, will the uninsured flock to Massachusetts? Is there something that can be done at the state level?

DR. BUECHLER: I don't know much about this, and somebody here might know more. It's called the Healthy Indiana plan. FQHCs have social workers and they've been handing out applications like crazy to underserved people without insurance. It seems like people are very interested in a subsidized - I think it's a highly subsidized - insurance product. I don't know enough about it to discuss it in depth, but it seems to me that people that don't have insurance are very interested in the Healthy Indiana Plan. Just as Dr. Carroll said, there's no way they can possibly afford it. So an expansion of that plan might work.

DR. CARROLL: I think that a state plan, if it was incredibly well done, could have great potential. I have to be honest. I don't think most of the state plans that have been put forth are necessarily going to accomplish their goals. They don't go far enough in my estimation, and in some sense the fact that they take half steps makes them less likely to succeed in some ways than doing nothing at all. This is because a half step that increases costs and provides very limited benefits makes any attempted reform look impractical and economically unsound.

Additionally, there are a lot of problems associated with trying to implement healthcare reform at the state level. For example, what happens when people want to move from one state to another? How would they report their 
insurance? There are actually legal ramifications, which likely all of you are more expert in than I am, and they're not really all that different than the ramifications at the national level. So is it possible that partial state reform could succeed? Yes, but I actually think it's probably less likely to succeed than the whole step of doing it at the national level.

DR. ORENTLICHER: Okay. Thank you. Let's turn to the next question. Compensation seems to be one of the problems. Specifically, there seem to be problems involved in compensating specialists more than primary-care physicians, and compensating for treatment rather than for prevention. The capitative compensation system pays providers to keep more patients healthy. In other words, the capitative compensation system pays a certain amount for each patient. That's all you have, and so it's in your best interest to keep them healthy, because the less treatment they need, the fewer dollars are required. Why has capitation not been more successful?

MR. GUTWEIN: Well, let me just offer perhaps a couple thoughts on that. I work in a system that is essentially capitated. I'll apologize upfront for shamelessly bragging about the system that I work in. I work at Wishard Health Services. We're the second-largest state hospital system in the country, with over 1.2 million outpatient visits a year. We are essentially a capitated system because we get a fixed pile of money that we beg, borrow, and steal to collect. Then we try to serve every patient that walks in our door. As a result, our incentives are precisely to serve each patient in the most effective, lowestcost way that we can. In other words, our incentives are actually precisely the opposite of most healthcare providers. Most healthcare providers get paid every time they perform - that's assuming they have a payer - a procedure on a person. Therefore, every time they do a procedure they get more money in the door, so their incentives are to do as many procedures as they possibly can. Conversely, we are incentivized to too make sure that patients become as healthy as they possibly can as quickly as possible, and to get them out the door so that someone else can come and fall into an empty bed in the middle of the night if they need to.

It turns out that in our capitated system our cost per patient is in the ninetieth percentile in the country. In other words, ninety percent of the hospitals in the nation have a higher cost than we have. Only ten percent have a lower cost, and that includes hospitals in nice suburban areas that have very highlyeducated and healthy patients. Actually, our patient base is a pretty unhealthy patient base because we deal with people who have a lot of problems. I think the reason why we have such a high-quality and low-cost system is that we really do attempt to drive people to primary-care.

We have a system that works very hard to ensure that as much primarycare is provided as possible. By primary care, I mean care provided in a continuum that finds illnesses at the earliest possible moment, works with patients to give them preventive care, reduces the use of specialists, and keeps people 
out of the emergency room. All of those things drive down healthcare costs. So I think that our system, because we don't have an incentive to try to provide unnecessary care, provides a pretty good bang for the buck when you benchmark us nationally.

Now, capitated systems have been unpopular for the private insurance system because managed care tries to tell people that they can't go to a doctor at a certain time - even if they want to go - and second-guesses the decisions of physicians and patients. Managed care does this, in part, because we don't have a fully-integrated healthcare system that can serve as the capitated portion of the system. In other words, it works for us because we are both the payer and the provider. Therefore, when we render medical care we focus on providing the lowest cost highest quality care for the patient. When the provider is not the entity that's capitated, but rather the payer, then a perverse incentive is created to try to actually eliminate care. That's why capitated systems, I think, have been extremely unpopular with all of the physicians who've been on the other side. The Kaiser Permanente system has actually been an awfully successful system in terms of lowering costs and increasing quality. The Kaiser Permanente system is a system like ours where both the provider and the payer are in essence the same entity. So I think there's great promise with the capitated system, but not with the kind of capitated system where the capitation is only at the payer level and not the provider level.

MR. SCHMITZ: I'd have to agree with Mr. Gutwein on a lot of that. One of the things that you run into frequently is the notion that insurance companies should own physicians. Anthem got into this back when it was just Indiana Blue Cross many years ago. Back then we actually tried owning physicians. We failed miserably at it. We could not run a physician's office. Conversely, one of the things that you'll see with capitated products is that physicians are excellent at what they do. They're excellent at rendering care and trying to get people back to a healthy state. They're not very good, however, at being actuaries, and I think that's why you run into difficult situations.

Another thing to consider is that you don't have a lot of large groups. I know there's been a lot of discussion throughout the day about the size of risk pools. As the size of a population increases, so too does the predictability of the costs associated with that population. This allows insurance companies to create better risk models. Throughout Indiana though, you probably could count on a couple hands the number of physician groups that have enough PCPs or overall physicians in their group to take on the amount of risk that is necessary to affect the overall outcomes without really putting the groups themselves at risk financially.

DR. ORENTLICHER: Other comments? Okay. Then let's turn to another question. What is the role of for-profit entities in healthcare? If they exist as a necessity for the free market to function, then how do for-profit insurance companies justify vertical integration of pharmacy programs which also 
limit competition in patient choice? Are for-profit hospitals and other entities good or bad for our healthcare system?

DR. CARROLL: Obviously, we're all going to have different opinions on this topic. I personally think that it really isn't logical for for-profit organizations to function in our healthcare system. Let's be honest about how insurance works, honest with no moral judgment. An insurance company makes more money by covering more healthy people and fewer sick people. It really only makes intuitive sense that the less money you have to put out, because your people are healthy, the more money you will take in, and the higher the profits you will make. Any for-profit insurance company that disputes that analysis should really be talking to their shareholders, because that's obviously how they make money.

Whether it's good or bad, in order to make more money, insurers must to some extent cherry-pick their patients. You either have to go after the healthy people and not cover the sick people, or you have to try to limit what you cover so you're not putting out too much money. Again, that's the reason you have to get a physical when you get insurance. That's why you have to provide a detailed medical history, so that your insurer can see what your prior expenses were. That's how for-profit insurance works, and it's difficult to argue how it could work on a very large scale.

If the for-profit insurance people are only going to cover the healthy people, then the rest of us are stuck picking up the tab for the sick people, and that's what we're doing right now. We've got Medicare and we've got Medicaid. That means we're covering the extremely poor and the elderly, two of the sickest, most expensive populations in the United States. At this point, private insurance covers about two-thirds of the people in this country and actually pays for about one-third of the cost. That's how they make their money. The government covers about one-third of the people, the most expensive one third and pays for two-thirds of the cost. That's why they can't afford to reimburse very much. That's why it always looks like they're hemorrhaging. There's nothing inherently wrong with the government system, nothing inherently wrong with the way that Medicaid and Medicare work. They're just hampered by their expenses.

Look at it this way. I have private insurance, but every year my insurance rates go up. The Medicare rates to some extent have been static since they were put in to effect. In essence, Medicare charges you a fixed percentage of your pay check. They can't raise their rates. Yet every year they're forced to cover more people because more people are reaching the sixty-five and above age bracket. They're forced to cover more costs and they continue to do it without raising their rates. But, private insurance gets to raise their rates whenever they want, and they can cover more and more healthy people each year. That's how they make their money. To try to integrate those two systems would be very difficult. They won't mesh. 
Now, perhaps there are other models that would allow private insurers to make money on top of a national insurance system. That's how Medicaid supplements work. That's perfectly plausible. There is no way that both systems could be in direct competition with each other though. As long as private insurance companies are going to make money by covering healthy people, a public system would find it impossible to function effectively at the same time.

DR. BUECHLER: I'd like to hear the answer from the largest profitmaking company in Indiana (Anthem/Wellpoint).

MR. SCHMITZ: When I look at hospitals, whether they are referred to as not-for-profit or for-profit, I recognize the fact they're in business to stay in business. We don't want to see any of the not-for-profit hospitals that we deal with every day go bankrupt. We don't want to see them close their doors, or have an issue with regard to overall financing. We want to see our hospitals to stay in business.

In regards to Dr. Carroll's comments, Anthem has recently expanded its role. At one time, we did only offer commercial health insurance. If you look at some of the risk pools that we have today, however, you will see that we have some very tough customers. Indiana's a highly-immunized state. There has been a lot of the smoking on the job. There are still factories out there with cigarette machines in their plants and employees that eat fast food every day. That hasn't stopped us. Today, we serve the Medicare population, two years ago we got into the Medicaid population, and now we have recently gotten into serving the Healthy Indiana population. It's not about denying care. It's not about charging more to make a profit. What we've found is that employers, the State of Indiana, and the federal government, come to private payers and say, "Look, here is the overall risk. Help us manage it. Anthem, MDwise, and United, help us manage the overall risk. Help us manage the care. Help these patients get to the proper physician or provider. Let's use the services properly."

Mr. Gutwein was correct when he stated that consumer incentives like gift cards or other small incentives can be helpful. We use incentives a lot with our Healthy Indiana population. We use them with our Medicaid population. We're managing the risk. We're helping these people get to their primary-care visits. We make sure that there are bus lines, and if they don't have the transportation, we get them to their appointments so that we can reduce that overall long-run cost in care. So at the end of the day, whether you're for-profit or notfor-profit, you're in business to stay in business. You can't stay in business and lose a lot of money.

MR. GUTWEIN: I work for a public hospital that is there to treat the indigent and to serve, so let me take a moment to defend the for-profit hospitals. To piggyback on Mr. Schmitz's point, I want to point out that the system we have right now requires payers, and principally insurance-carrying payers, to 
subsidize the healthcare delivery system for nonpaying patients. It's a system that mandates cross subsidization. In other words, if you put a hospital downtown, we expect that hospital to serve every single patient, including a fair number of nonpaying patients, and all of us that have insurance are expected to subsidize those nonpaying patients. That creates for the business model and the healthcare provider the dilemma of how to stay in business when you have lots of nonpaying patients coming to you.

Every healthcare provider tries to manage what's called the payer mix. In other words, how many patients have Medicare, how many have Medicaid, how many have nice insurance cards, and how many are uninsured? And it turns out that perhaps the most effective way to manage your payer mix is geography. In other words, to put your hospital where the most payers are and the least nonpayers are. The second most effective way is to be a for-profit entity so that the government mandates don't apply to you, and you get to decide who comes into your hospital and who doesn't. And those facts are highly rational, predictable behaviors that result from the healthcare system that we have. It's precisely what you would predict will occur if you set up a system that has forty-seven million uninsured, then put in place laws that require every hospital that has an emergency room to treat every patient that walks through its doors.

I don't believe that for-profit hospitals are run by morally bad people who are somehow trying to put one over on the rest of us. They're rational economic actors that are reacting to a broken system that needs to be fixed. I think we need to provide universal coverage for everyone. That way we don't have the perverse incentives that lead to the construction of unneeded hospitals in suburbs and hospital flight from areas of high density where people have enormous medical needs but lack access. It is a systemic problem to me, not an individual issue of moral blameworthiness focused on the owners and operators of for profit hospitals. So what I'm actually doing -

DR. CARROLL: Just to be clear. I'm making no moral judgments. I said exactly the same thing; that this is how business operates. This is how insurance companies -

MR. GUTWEIN: Actually, I was agreeing with you completely, Dr. Carroll.

DR. CARROLL: Sometimes it's very easy to jump to the conclusion that a moral judgment is being made. I make no moral judgments. What we have both described is rational business decision making on the part of healthcare providers. That's how they make money. Everybody agrees. I just don't think it's appropriate.

DR. BUECHLER: I want to apologize to Mr. Schmitz because I made a cynical comment earlier. In reality, I don't have a problem with for-profit insurance companies. I do think that they need to be much more transparent 
about what they are offering, to whom they are offering it, and under what circumstances it will be offered, so that there can be true competition out there. With big employers there is transparency, because they have people that analyze it. I do have a problem, same kind of a problem, though, with the forprofit hospital system and the cherry-picking that definitely goes on, because it impacts all of the not-for-profits. But that's just our system. I can understand it. It just isn't good.

DR. ORENTLICHER: Okay. Mr. Gutwein, did you want to complete your statement or respond?

MR. GUTWEIN: No.

DR. ORENTLICHER: Ok. Then let's turn to another question. My son is a physician. His wife is a nurse practitioner. For identical care she's paid a fraction of what he is. Should we not be making better use of nurse practitioners and nurse anesthetists? How much would that do improve our healthcare system?

DR. BUECHLER: Well, I've had a lot of experience with mid-level providers, and I am a strong advocate of nurse practitioners and physician's assistants, especially when they work in a collaborative practice. I have a bit of a problem with their independent practice based strictly on education. The education is significantly different, but most of what you see in primary-care is calm and ordinary and can be taken care of by any well-educated person. Should there be a discrepancy in payment? There should be a discrepancy. After all I went through eight years of education after college. But it should be slight. Really, the only thing that is saving primary-care right now for hundreds of thousands of people in our country is mid-level providers - they're doing a good job - but we should all be working collaboratively together. There are plenty of patients to go around.

DR. CARROLL: It's interesting because the question really made me think about how it would fix the system. The question gives me pause only because it suggests that by fixing one aspect of the system, we're going to improve everything at the same time, including cost, quality, and access. In reality though, it's pretty much impossible to lower costs, improve quality, and improve access all at the same time. There are quite a few studies that show that if we get everybody in the country to stop smoking tomorrow the long-term health costs of this country will go up significantly. That's right, if everyone quits smoking our healthcare costs will continue to rise, because people are going to live longer. It's a good, but it's going to cost us money. Conversely, I can drop the healthcare costs in this country tomorrow if I kill everybody who's in a hospital today. That would not be a good, but it would reduce costs. 
Clearly, doing good, improving quality, and improving access are all going to cost money. Access to mid-level nurse practitioners would improve access immensely. Would it improve quality? I don't know if it's been proven one way or the other. However, such access might improve the quality of primary-care generally. Would it improve costs at the same time? I don't think so. More mid-level nurse practitioners would likely be able to see more patients, but I have no idea how much their training would affect the situation. It's very likely that it would improve quality and improve access at the sake of cost. Is that fixing the system? That's for everybody to decide. You have to sort of prioritize your cost, quality, and access. But there is no magic bullet that would hit all three at the same time.

MR. GUTWEIN: One really final comment on this. Interestingly enough, the pay differential between certain physician extenders and physicians is not that great anymore. I think it was commented that a new primary-care physician earns about $\$ 125,000$ a year. These for-profit companies that have nurse in a box, the Minute Clinic, those places, they pay the good nurses $\$ 90,000$ a year. So it's a relatively small differential now, which shows how valuable for the business model the nurse practitioner is.

MR. SPEER: Their use is somewhat additive. I certainly support the appropriate use of physician extenders, but I think the key is collaboration. Under the right collaborative circumstances, I think they have a very important role to play. There's just not that much cost difference between them anymore. They do create more access. I think studies also show that there's greater patient satisfaction with interaction with some of the extenders. But the extenders are seeing fewer patients in a greater period of time, so it would make sense they'd have higher satisfaction.

MR. SCHMITZ: If I can add one more comment along with that. Wellpoint and Anthem were recently approached by a physician extender group to actually enter the business of doing deliveries outside of a hospital system. I'll be honest with you, we wrestled with this. It would improve access to care, but what about quality? Is there a price worth paying for quality? I think Dr. Buechler was right on the money when he questioned where we need to draw the line with regard to how much a physician extender can be permitted to do as compared to a physician.

DR. ORENTLICHER: This question kind of ties into one of Professor Annas's points about denial of death. Providing care for sick babies, especially premature infants that may require up to four months of inpatient care, is extremely expensive for Medicaid and the rest of the healthcare system. What is the line that should be drawn on extraordinary measures for these babies? Dr. Carroll, I think you said it was eighty-five percent of the cost from twenty percent of the population. How much of this is inappropriate? Are we now draw- 
ing lines where they should be drawn? Or is it just that chronic illness is very expensive?

DR. CARROLL: That's an unbelievably excellent question, and if you think there's an easy answer, I can tell you that there just isn't. The problem is that right now our healthcare system is so fractured that there is no way to even begin to address that question. Today there are differences in insurance, in coverage, in where patients live, in patient's access to the system in general, and in the fact that different hospitals can do different things. So we can't even begin to address the question. Ideally, we'd like it to.

I think that these are questions that we have to address as a nation. As we see healthcare costs spiral and go out of control, as we see quality start to go in the toilet, as the quality of our access to care continues to decline, we need to, as a country, make a decision about the way we want to spend our money. Call it rationing if you will. There's a limited amount of money in the pot. There's only so much we can spend, and we have to decide where it's going to go. Ideally, these decisions should be made by a group of people from very different walks of life. People, who come from various backgrounds, be they medical, legal, or ethical. We have to have groups that actually try to make these decisions about how to spend money. Other countries do this. We attack them for it. We tell them that they're rationing care and that they're sentencing people to die. But that's what happens when you start making these choices. You can only do so much.

At this point we ration, to some extent, by insurance. If you have it, you have a good shot at getting the care you need. If you don't have it, you probably won't. You might if you're lucky. But that's how we ration right now. It makes a lot more sense to ration, if you want to use that word again, by some sort of ethical or guiding principles that we all come to terms with and agree on. We're probably going to have to do it someday as care gets more and more expensive, as drugs and procedures get more and more expensive, and as the incremental cost effectiveness of each new advance becomes smaller and smaller. Is it an important question? Yes, absolutely. Are we going to have to draw the line somewhere at some point? Yes, probably. But wouldn't it better to draw it in relation to a national system where we're all agreeing to it together, than for each of us just to roll the dice and hope for the best?

MR. SPEER: We did $\$ 117$ million in charity care last year in the state of Indiana. My guess is - and I don't have a precise figure - a significant portion of that was dedicated to premature neonatal care for children. There is no bright line, and it's troubling to me that we would suggest there is a bright line. I'm unaware of any insurance product offered in this state that's ever prevented a child from getting needed care from Wishard, St. Vincent, Clarian, or any other hospital. There are even neonatal transports in the state in all ninety counties that move a patient to exactly where they need to be. Some of those children are in the hospital for months before they get to go home. I don't think 
there's a bright line, and I don't think any child has been denied care from insurance.

DR. CARROLL: Let me make clear that I'm not implying there is. Certainly I think we withhold prenatal care to some extent and that some people have better access to prenatal care, which can lead to prematurity. I absolutely agree, however, that I have never seen anyone withhold care. I'm a pediatrician. I've never seen that bright line, nor do I think probably there is a bright line there. However, there has to be a line at some point. In some respect to our healthcare system, we have to come to terms with the fact that there's going to be a line somewhere for somebody. Again, we can't spend unlimited money and at the same time achieve the best quality and the best access.

The key is coming to terms with what's important. If we as a nation decide that, yes, we want to spend as much money as possible on everybody then we're admitting upfront we're going to limit access and quality. And if that's what we agree to as a country, so be it. That's America, and I have no problem with that. But I think it needs to be a fair and open discussion amongst all of us, and that we all need to make that decision together. Most people seem to be in agreement right now that we need to cover everybody. Everybody at least needs access to the system through some type of insurance.

Again, I'm not implying that anyone's withholding care. I'm not implying that insurance is causing people to die, or not covering infants, or that people don't care. I'm part of the system. We all drank the Kool-Aid. We all want to do "good." Even healthcare providers that disagree with my stated positions completely are not evil. Nobody wants to harm anybody. Everybody wants to do "good." It's just a question of how to do the most good for the most people, and how to determine what our national priority is.

MR. SCHMITZ: I truly like this question, because the best way to save money in cases like this is to never have the case occur in the first place. That was what we were trying to talk about with regard to incentives around getting prenatal care. All of you are aware from the media that combinations of some cardiac drugs and Viagra led to some pretty serious issues. The problem is that there's no data forum that cross-references these drug claims. We have a product that will monitor and match up these claims so that we can alert a PCP if an adverse interaction is likely to result from some combination of drugs that have been prescribed. We also keep an eye out for situations where patients might need more information in order to make the best health related decisions. And when we think a patient or a physician needs assistance we get out there right away and we start working with them or we send them literature and information. You spoon feed as much as you can, so that you never get into a bad situation. That's truly how we can prevent the most mishaps.

DR. ORENTLICHER: I want to ask just one more question. One of the things that we've seen - and Dr. John Westbury and Dartmouth are pioneering 
studies - is the development of different practice patterns from one state to another. Even within a particular hospital, different doctors have very different practice patterns that are hard to explain. This is not based on patient differences. Is that something that's unique to the U.S.? Do you see this in other healthcare systems? Is that something that would be addressed by changing to Medicare for all? Is it something that needs to be changed? How do we address this problem? I think that one of the more recent examples of this phenomenon is that the Cleveland Clinic does certain heart procedures for half the price of a nearby private clinic, and there's no good reason for the higher rate at the nearby clinic. Is that being addressed? Can it be addressed? Is this a worldwide phenomenon, or is this particular to the U.S.?

DR. CARROLL: I think that it's a problem that's probably not limited to the U.S. The difference between our country and other countries is to some extent an issue of accountability and transparency. In most other countries, the healthcare systems are more transparent. And because hospitals in those countries are not in competition with each other and not for profit there's a little more data sharing. The other consideration apparent here is that electronic medical records are big in other countries, so they have easy access to data. Data that would take us years and millions of dollars to try to cobble together with wire and twigs in the U.S.

Other industrialized nations can, to some extent, pull up records regarding how many people in that country had a procedure in a particular area almost instantly. In the U.S., we have no way of easily accessing that type of information. So in the U.S., it takes very time intensive and expensive studies to discover these differences, let alone begin to address them. Also, if you only have one recordkeeping or healthcare system, it's a little easier, from the payer standpoint at least, to implement change, to say we're going to be paying for this procedure versus that one, going to shift to using this medication over that one. It's a lot more difficult in the U.S. because we have record keeping differences, not just amongst the various states, but also amongst hospitals in the similar geographic areas. These inconsistencies will continue as long our system is not transparent.

DR. ORENTLICHER: Okay. Well, thank you all for coming today. This concludes our panel discussion. 